\title{
Predator visits to acclimatization pens: implications for the soft-release of gallinaceous birds
}

\author{
David A. Keiter and Rebekah E. Ruzicka
}

\begin{abstract}
Predator visitation to acclimatization or soft-release pens containing captive translocated animals has the potential to cause sub-lethal effects or physical injury that could influence post-release survival and establishment. No previous study has examined potential interactions between captive and resident animals during pre-release holding periods. We monitored seven holding pens containing wild-caught northern bobwhite Colinus virginianus or scaled quail Callipepla squamata in the Rolling Plains Ecoregion of Texas, USA, using remote camera systems. Our objectives were to determine if resident predator species and conspecifics visited holding pens, and to characterize visits by species, frequency, duration and behaviour. We recorded visitation to holding pens by four potential predator species. Although most visits by mammalian predators were short in duration, northern raccoons Procyon lotor were observed spending extended periods of time at holding pens. We also recorded resident scaled quail and northern bobwhite quail visiting holding pens containing conspecifics. We recommend that future studies using a soft-release technique in which captive animals are held at the release site consider the potential impacts of predator visitation to holding pens, and methods to mitigate those impacts.
\end{abstract}

Keywords Acclimatization pens, conspecifics, quail, Rolling Plains Ecoregion, soft release, sub-lethal effects, Texas, translocation

\section{Introduction}

any species of gallinaceous grassland birds in North 1 America have experienced long-term population declines concurrent with geographical range contraction (Schroeder et al., 2004; Brennan \& Kuvlesky, 2005; Brennan, 2007; Sauer et al., 2008). The most widely accepted drivers of large-scale decline of these birds are loss, fragmentation and

DAVID A. KeIteR* (Corresponding author) Rolling Plains Quail Research Ranch, 1262 US-180, Rotan, Texas, USA 79546. E-mail david.keiter@gmail.com

Rebekah E. Ruzicka $\dagger$ Texas A\&M AgriLife Extension Service, Dallas, Texas, USA

${ }^{\star}$ Current address: University of Georgia, Savannah River Ecology Laboratory, Warnell Department of Forestry and Natural Resources, PO Drawer E, Aiken, SC 29802, USA

†Current address: Department of Fish, Wildlife, and Conservation Biology, Colorado State University, Fort Collins, USA

Received 3 April 2017. Revision requested 24 May 2017.

Accepted 13 June 2017. First published online 26 September 2017. degradation of grassland habitats across the continent (Drum et al., 2015). These declines are a serious threat to the persistence of populations of gallinaceous bird species, often necessitating some form of conservation action (Brennan \& Kuvlesky, 2005).

In an effort to mitigate these declines, research has focused on translocating wild-caught animals back to their historical ranges, either to establish new populations or augment existing populations (Terhune et al., 2006a,b; Baxter et al., 2013; Scott et al., 2013; Troy et al., 2013). Translocation programmes often employ a soft-release technique in which animals are held captive on site prior to release (Snyder et al., 1999) in an attempt to condition them to the novel environment (Letty et al., 2000), improve site fidelity (Kinsey, 2011), and facilitate recovery from capture myopathy through the provision of food and shelter from predators and inclement weather conditions (Thacker et al., 2016). It is important to minimize injuries and stress to captive animals during this holding period to ensure maximum survival of translocated animals post release (Teixeira et al., 2007).

However, captive birds may act as an attractant to predators while held in captivity. Research has found that perceived predation risk can increase stress responses and decrease reproductive output and quality of offspring in a number of vertebrate taxa (Sheriff et al., 2009; Zanette et al., 2011). This suggests that although predators may not be able to access captive animals, their immediate proximity at holding pens could cause physiological stress or other sub-lethal effects, and/or physical injury if captive birds attempt to flee while confined. Although many studies have investigated the fate of soft-released animals (e.g. Bright \& Morris, 1994; Letty et al., 2000), to our knowledge no previous study has monitored interactions between captive and resident animals during pre-release holding periods. Assuming that a predator's presence at a containment device could act as a stressor to captive birds inside, an evaluation of visitation rates by resident predator species may provide insight into the potential risk to captive animals prior to their release.

Where translocations are used to augment existing populations there is the possibility of interaction between captive animals and resident conspecifics. Captive-resident interactions may have implications for the success of translocation efforts if the interaction facilitates the integration of translocated animals in resident populations. In general, site fidelity of social species is increased by building social relationships through a confinement period prior to release (Moseby et al., 2014), and translocations tend to be more 
successful when conspecifics are still present on the release site (Griffith et al., 1989).

We used camera traps to monitor holding pens, or acclimatization pens, containing wild-caught captive northern bobwhite Colinus virginianus and scaled quail Callipepla squamata during an ongoing translocation project in the Rolling Plains Ecoregion of Texas. Our goals were to quantify the frequency and duration of visits by resident predator species to acclimatization pens holding captive quail, and visits to the pens by resident conspecifics, and thus determine the existence of potential positive or negative interactions between the resident wildlife community and translocated gallinaceous birds prior to their release.

\section{Study area}

The Rolling Plains Quail Research Ranch (1,910 ha) is a nonprofit ranch dedicated to quail research and conservation, located in Fisher County in the Rolling Plains Ecoregion of Texas (Fig. 1). It is characterized by prairie grasslands at 500-900 $\mathrm{m}$ altitude, with little topographical variation (Ruzicka et al., 2016). A variety of potential quail predators have been recorded on site, including bobcats Lynx rufus, coyotes Canis latrans, badgers Taxidea taxus, raccoons Procyon lotor, striped skunks Mephitis mephitis, rattlesnakes Crotalus spp., and hawks (Accipiter and Buteo spp.). Populations of northern bobwhite and scaled quail are also established there.

\section{Methods}

Wild northern bobwhite and scaled quail were trapped using walk-in funnel traps baited with sorghum at four sites in the Rolling Plains and Edwards Plateau ecoregions, within a $250 \mathrm{~km}$ radius of the ranch. Quail were placed in eight holding pens on site in March 2014 (earliest 14 March). Holding pens were placed within $10 \mathrm{~m}$ of roads to facilitate resupplying of food and water to captive birds. All birds were captured, handled and held in accordance with Texas A\&M University Institutional Animal Care and Use Committee guidelines (AUP \# 2013-004A). Holding pens were modelled on a commercially available quail containment device, the Surrogator (Wildlife Management Technologies, Witchita, USA; described in Thacker et al., 2016). Each pen was $1.2 \times 2.4 \times 0.4 \mathrm{~m}$ in size, incorporating metal grates in the sides so captive quail could see their surrounding environment. We supplied each with a gravity-fed food trough and water attachment; holding pens contained sufficient food and water resources for the duration of captivity, to minimize the necessity for human contact. We placed a number of translocated quail $(\bar{X}=13.4 \pm S D$ 2.6) in each holding pen, separated by species, for 33-39 days (final release 25 April 2014). Food and water resources were added to holding pens when quail were added; food consisted of grain sorghum and a commercially available chicken feed protein supplement. We timed the release of captive quail to coincide with the start of the breeding season in the Rolling Plains (i.e. early May; Brennan, 2007).

To monitor predator visitation to holding pens we placed infrared trail cameras (Moultrie MFH-I-40, Ebsco Industries, Inc., Birmingham, USA; Bushnell Trophy Cam Model 119537, Bushnell Outdoor Products, Overland Park, USA) at four holding pens containing scaled quail, and three holding pens containing northern bobwhites. Each pen was placed within $500 \mathrm{~m}$ of another pen containing individuals of the same species, and pairs of pens were placed $1.69 \pm$ SE $0.728 \mathrm{~km}$ apart, on average, to distribute translocated birds throughout the study site (Fig. 1). We placed cameras c. $3 \mathrm{~m}$ from pens, facing the narrow end of the pens so that any activity in front, to the sides, or on top of the pens would be captured during the acclimatization period. Cameras were motion-activated and set for a 1-minute delay between trigger activations. We recorded number and duration of visits by resident predator and conspecific quail species to holding pens, and standardized visitation data to visits per 100 camera-days (Bengsen et al., 2011). We considered visits to be separate if the interval between photographs was $\geq 30$ minutes (Kelly \& Holub, 2008).

\section{Results}

We recorded 18 visits by predators and 209 visits by resident quail species to holding pens during the acclimatization period $(\bar{X}=35.8 \pm$ SD 2.2 days; Plate 1$)$. Predator species observed at holding pens containing captive quail included badgers, bobcats, raccoons and Cooper's hawks Accipiter cooperii (Table 1). Badgers and bobcats were observed at holding pens 1-2 times each, for only 1 minute per visit, whereas raccoons visited repeatedly (14 times) and for longer periods of time (Table 1). One visit by a Cooper's hawk was also observed, in which the hawk spent 92 minutes attempting to enter the holding pen. Predators visited four of seven monitored holding pens ( $57 \%$ ), and the majority of visits $(83 \%)$ were to holding pens containing scaled quail. The visits by the bobcats, badger and Cooper's hawk occurred within the first 3 weeks of quail captivity $(6,21$ and 18 days, respectively, following addition of quail). We did not photograph any raccoons until the fourth week of quail captivity; however, after detecting holding pens, raccoons were photographed spending up to 1.5 hours per visit on repeated visits attempting to enter the holding pen (Plate 1). The bobcat and Cooper's hawk were also photographed attempting to enter the holding pen, whereas the badger was photographed in proximity, without obvious evidence of interaction. Camera traps captured resident wild quail visiting holding pens numerous times (Plate 1). Resident scaled quail visited holding pens containing scaled 


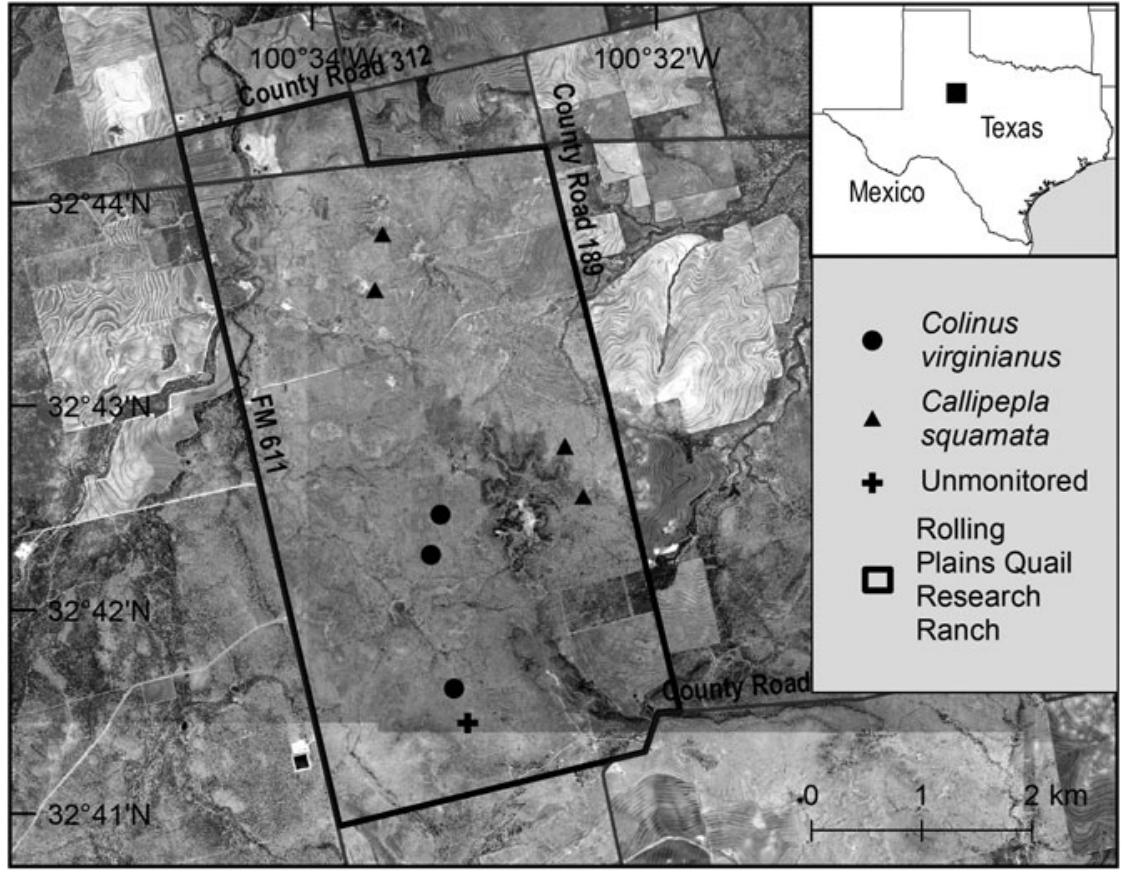

FIG. 1 Locations of acclimatization pens holding translocated northern bobwhite Colinus virginianus and scaled quail Callipepla squamata on the Rolling Plains Quail Research Ranch in Texas, USA, in 2014. All but one of the pens were monitored by camera trap.

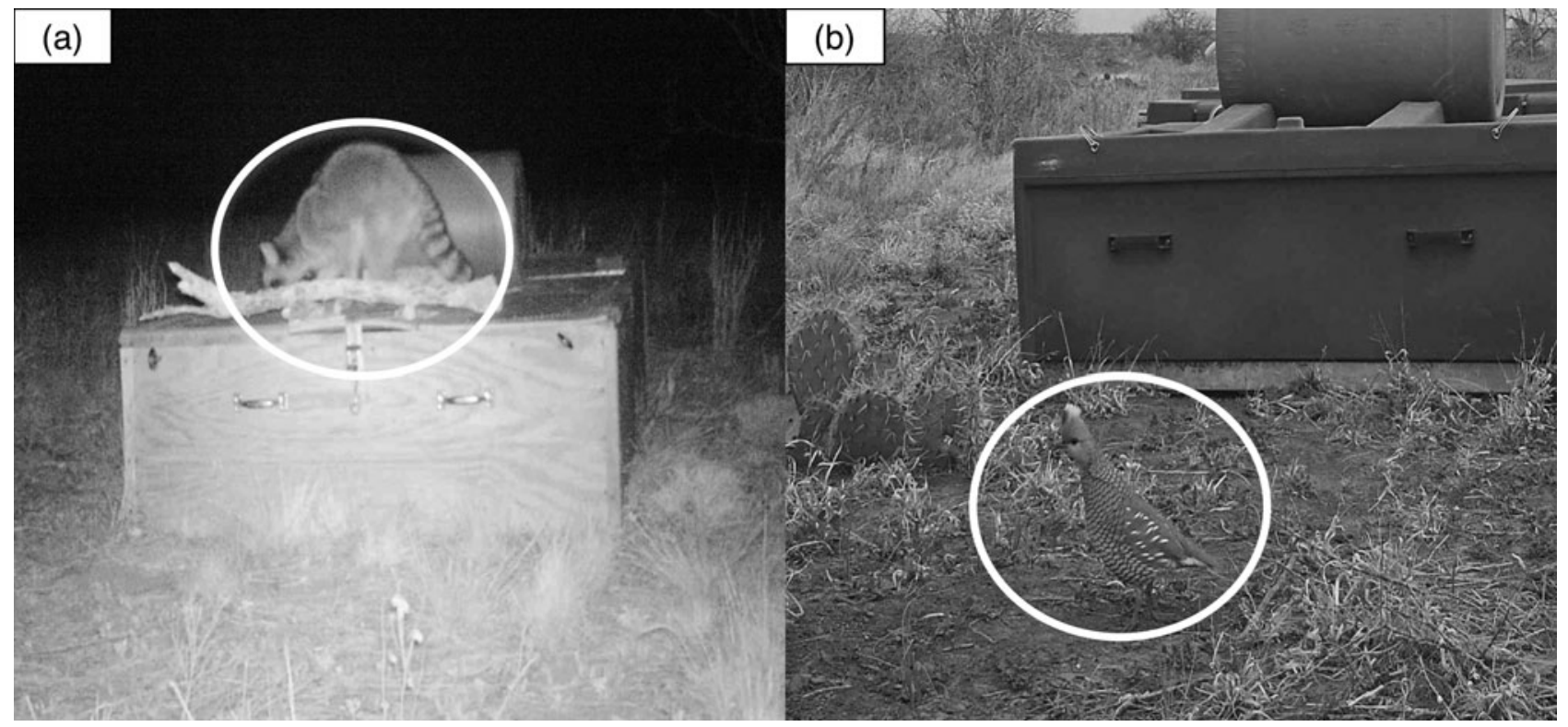

Plate 1 Camera-trap photographs of (a) a northern raccoon Procyon lotor attempting to enter a holding pen containing c. 13 translocated northern bobwhite Colinus virginianus, and (b) a resident scaled quail Callipepla squamata in proximity to an acclimatization pen holding c. 13 captive translocated scaled quail at the Rolling Plains Quail Research Ranch (Fig. 1) in 2014.

quail frequently (52.86 visits per 100 trap-nights), with one visit lasting as long as 4.5 hours. Resident northern bobwhites also visited conspecific holding pens, although at a lower rate than scaled quail (3.11 visits per 100 trap-nights). A northern bobwhite was recorded visiting a holding pen containing scaled quail once, but scaled quail were never observed visiting holding pens containing northern bobwhites. Resident scaled quail visited holding pens containing scaled quail for longer periods of time $(\bar{X}=22.1 \pm \mathrm{SD} 38.0$ minutes $)$ than resident northern bobwhites visited pens holding captive northern bobwhites ( $\bar{X}=4.2 \pm$ SD 7.2 minutes).

\section{Discussion}

This study was the first to monitor interactions between captive and resident animals during an acclimatization period, despite the potential implications for overall 
TABLE 1 Standardized rates of visitation by predators and resident conspecifics to holding pens containing captive northern bobwhite Colinus virginianus or scaled quail Callipepla squamata in the Rolling Plains Ecoregion of Texas, USA, during March-April 2014, with maximum and mean duration of visits.

\begin{tabular}{llcc}
\hline & $\begin{array}{l}\text { Visits per 100 trap-nights } \\
\text { (total no. of visits) }\end{array}$ & $\begin{array}{l}\text { Maximum duration of visit } \\
\text { (minutes) }\end{array}$ & $\begin{array}{l}\text { Mean duration of visit } \\
\text { (minutes) }\end{array}$ \\
\hline Predators & & & 17 \\
American badger Taxidea taxus & $0.4(1)$ & 1 & 1.0 \\
Bobcat Lynx rufus & $0.8(2)$ & 90 & $16.6 \pm$ SD 23.1 \\
Raccoon Procyon lotor & $5.6(14)$ & 92 & \\
Raptor Accipiter and Buteo spp. & $0.4(1)$ & 22 & $4.2 \pm$ SD 7.2 \\
Quail & $4.0(10)$ & 269 & $22.1 \pm$ SD 38.0 \\
Northern bobwhite Colinus virginianus & $79.3(209)$ & & \\
Scaled quail Callipepla squamata & &
\end{tabular}

translocation success. Camera trapping revealed that predators visited holding pens while quail were captive. This was not unexpected, as the holding pens represented a potential food source on the landscape. Although the quail and food contained within the pens were unavailable, they may have served to draw predators to the area in a manner similar to supplemental feeding routines (Godbois et al., 2004; Selva et al., 2014). However, overall the number of predator visits to holding pens was relatively low; the majority of predator species visited 1-2 times for a period of 1 minute each.

Many studies have highlighted the importance of reducing physiological stress in translocated animals to improve overall survival (e.g. Letty et al., 2000; Teixeira et al., 2007). Visitations by predators to acclimatization pens have the potential to act as a stressor to the animals held captive, necessitating further empirical evaluation to improve translocation protocols and maintain animal welfare during acclimatization periods. When people approached the holding units containing captive quail, the birds exhibited fear responses, including attempting to fly while contained, resulting in superficial injuries. As such, relatively lengthy attempts ( $\geq 90$ minutes duration) by raccoons to enter holding pens, or repeated visitations (12 visits to a single holding pen by raccoons), may have the most potential for sub-lethal effects. Zanette et al. (2011) found that exposure of songbirds to increased perceived predation risk (e.g. auditory cues of local predators) caused a decrease in reproductive output in a field setting. In addition, increased stress hormone levels and decreased reproductive output have been reported for pregnant snowshoe hares Lepus americanus that were exposed to a perceived predator for 1-2 minutes every other day for a 15-day period in a captive setting.

We suggest researchers seeking to reduce potential stress to captive quail during the holding period may find it beneficial to limit the presence of specific predator species (e.g. raccoons) near holding pens. In our study, raccoons appeared to pose the greatest threat to the health of captive quail, as they were the only mammalian species recorded spending more than 1 minute per visit at holding pens, and repeatedly visiting holding pens; they were often photographed on top of the holding pens actively trying to enter for extended periods of time. Possible methods to limit predator visitation to holding pens could include reduced acclimatization periods, trapping and relocating or lethal control of predators, or the use of an exclosure, such as electric fencing (Sargeant et al., 1974).

In terms of post-release fitness there are two competing hypotheses regarding predator exclusion. It is possible that exposure to predators during the acclimatization period may have some potential benefits to translocated animals. Predation pressure on the reintroduced population is a leading cause of failure in many reintroduction programmes (Short, 2009). As such, emphasizing the exclusion of predators may be short-sighted, as it may leave translocated animals naïve and therefore more susceptible to future predation (Moseby et al., 2015). Predator avoidance training, in which captive animals are exposed to some sort of negative stimulus in conjunction with a predator cue, has been investigated in laboratory settings but has not been validated under field conditions (reviewed in Moseby et al., 2015). The quail we translocated were wild-caught and therefore probably already familiar with the predator community present at our study site; however, the exposure of captive quail to resident predators may have acted as an additional training experience, teaching them to better recognize certain predator cues and thus facilitating improved avoidance. However, it is also possible that these interactions could potentially improve predators' recognition of prey cues (e.g. search images; Nams, 1997) and thus have a negative effect on the survival of translocated animals post release.

Resident conspecifics, particularly scaled quail, also frequented holding pens containing captive quail. These visits were unexpected but could potentially aid in the establishment of captive individuals. Integration of translocated animals into resident populations is the primary goal of population augmentation efforts and is frequently used as a metric of translocation success (Baxter et al., 2013). Visitations by resident quail to captive quail in holding 
pens may provide opportunities for contact that could lead to assimilation of captive animals into wildlife populations, although further evaluation of this process is necessary. The presence of conspecifics on the landscape could also encourage translocated birds to stay in the area rather than dispersing long distances (Baxter et al., 2013). The resident quail that visited holding pens frequently were single birds, which may indicate they were unpaired birds looking for mates. Research to evaluate whether released captive birds breed more successfully when resident conspecifics are present at acclimatization pens would benefit understanding of the overall process of population establishment by animals translocated for purposes of population augmentation.

This small-scale study highlights areas of research necessary to refine soft releases of translocated animals. We found that acclimatization pens were visited by predator species, which could have sub-lethal effects on the animals within. Quantification of these sub-lethal effects and post-release vital rates is necessary to determine potential consequences on captive translocated animals. We suggest that additional studies be performed to determine stress responses of captive animals to predator visitation, and to relate survival of animals following release to prior visits of predators to acclimatization pens. This could be accomplished using various body condition measures in conjunction with intensive postrelease radiotelemetric monitoring. Further studies could be performed in controlled circumstances in which captive animals are subjected to standardized levels of predator exposure, and various measures of the impact of this exposure (e.g. cortisol levels, body condition measures, reproductive output) are taken (as in Sheriff et al., 2009). We also recommend that studies be undertaken to elucidate the potential effects of conspecific visitation to holding pens on integration of translocated animals into existing populations.

\section{Acknowledgements}

We thank the Rolling Plains Quail Research Ranch for support of this research, and D. Rollins, L. M. LaCoste, B. Koennecke, M. Downey, T. Berry, L. McCall and D. White for their help in implementing the research. We also thank J. B. Smith for his valuable comments and suggestions. Funding for this publication was provided through the Reversing the Quail Decline Initiative and the Upland Game Bird Stamp Fund, based on a collaborative effort between the Texas Parks and Wildlife Department and the Texas A\&M AgriLife Extension Service. All research was performed within the guidelines of the Oryx Code of Conduct.

\section{Author contributions}

DAK designed the experiment and collected the data; DAK and RER analysed the data and wrote the article.

\section{References}

BAXTer, R.J., LARSEn, R.T. \& Flinders, J.T. (2013) Survival of resident and translocated greater sage-grouse in Strawberry Valley, Utah: a 13-year study. The Journal of Wildlife Management, 77, 802-811.

Bengsen, A.J., Leung, L.K.-P., LAPidge, S.J. \& Gordon, I.J. (2011) Using a general index approach to analyze camera-trap abundance indices. The Journal of Wildife Management, 75, 1222-1227.

Brennan, L.A. (ed.) (2007) Texas Quails: Ecology and Management. Texas A\&M University Press, College Station, USA.

Brennan, L.A. \& KUvlesky, JR, W.P. (2005) North American grassland birds: an unfolding conservation crisis? The Journal of Wildlife Management, 69, 1-13.

Bright, P.W. \& Morris, P.A. (1994) Animal translocation for conservation: performance of dormice in relation to release methods, origin and season. Journal of Applied Ecology, 31, 699-708.

Drum, R.G., Ribic, C.A., Koch, K., Lonsdorf, E., Grant, E., Ahlering, M. et al. (2015) Strategic grassland bird conservation throughout the annual cycle: linking policy alternatives, landowner decisions, and biological population outcomes. PLOS ONE, 10(11), eo142525.

Godbois, I.A., Conner, L.M. \& Warren, R.J. (2004) Space-use patterns of bobcats relative to supplemental feeding of northern bobwhites. The Journal of Wildlife Management, 68, 514-518.

Griffith, B., Scott, J.M., Carpenter, J.W. \& Reed, C. (1989) Translocation as a species conservation tool: status and strategy. Science, 245, 477-480.

Kelly, M.J. \& Holub, E.L. (2008) Camera trapping of carnivores: trap success among camera types and across species, and habitat selection by species, on Salt Pond Mountain, Giles County, Virginia. Northeastern Naturalist, 15, 249-262.

KINSEY, J.C. (2011) Effectiveness of Surrogators ${ }^{\oplus}$ as a propagation tool for northern bobwhites in south-central Texas. MSc thesis. Texas State University-San Marcos, San Marcos, USA.

Letty, J., Marchandeau, S., Clobert, J. \& Aubineau, J. (2000) Improving translocation success: an experimental study of anti-stress treatment and release method for wild rabbits. Animal Conservation, 3, 211-219.

Moseby, K., Carthey, A. \& Schroeder, T. (2015) The influence of predators and prey naivety on reintroduction success: current and future directions. In Advances in Reintroduction Biology of Australian and New Zealand Fauna (eds D.P. Armstrong, M. W. Hayward, D. Moro \& P.J. Seddon), pp. 29-42. CSIRO, Victoria, Australia.

Moseby, K.E., Hill, B.M. \& Lavery, T.H. (2014) Tailoring release protocols to individual species and sites: one size does not fit all. PLoS ONE, 9(6), e99753.

NAms, V.O. (1997) Density-dependent predation by skunks using olfactory search images. Oecologia, 110, 440-448.

Ruzicka, R.E., Rollins, D., Lacoste, L.M. \& Wester, D.B. (2016) Factors affecting trapping success of northern bobwhites in the rolling plains of Texas. Wildlife Society Bulletin, 40, 605-610.

Sargeant, A.B., Kruse, A.D. \& Afton, A.D. (1974) Use of small fences to protect ground bird nests from mammalian predators. Prairie Naturalist, 6, 60-63.

Sauer, J.R., Hines, J.E. \& Fallon, J. (2008) The North American Breeding Bird Survey, Results and Analysis. Version 5.15.2008. USGS Patuxent Wildlife Research Center, Laurel, USA.

Schroeder, M.A., Aldridge, C.L., Apa, A.D., Bohne, J.R., Braun, C.E., Bunnell, S.D. et al. (2004) Distribution of sage-grouse in North America. The Condor, 106, 363-376.

Scott, J.L., Hernández, F., Brennan, L.A., Ballard, B.M., Janis, M. \& Forrester, N.D. (2013) Population demographics of 
translocated northern bobwhites on fragmented habitat. Wildlife Society Bulletin, 37, 168-176.

Selva, N., Berezowska-Cnota, T. \& Elguero-Claramunt, I. (2014) Unforeseen effects of supplementary feeding: ungulate baiting sites as hotspots for ground-nest predation. PLoS ONE, 9(3), e90740.

Sheriff, M.J., Krebs, C.J. \& Boonstra, R. (2009) The sensitive hare: sublethal effects of predator stress on reproduction in snowshoe hares. Journal of Animal Ecology, 78, 1249-1258.

Short, J. (2009) The Characteristics and Success of Vertebrate Translocations Within Australia. Australian Government Department of Agriculture, Fisheries, and Forestry, Canberra, Australia.

Snyder, J.W., Pelren, E.C. \& Crawford, J.A. (1999) Translocation histories of prairie grouse in the United States. Wildlife Society Bulletin, 27, 428-432.

Terhune, T.M., Sisson, D.C. \& Stribling, H.L. (2006a) The efficacy of relocating wild northern bobwhites prior to breeding season. The Journal of Wildlife Management, 70, 914-921.

Terhune, T.M., Sisson, D.C., Stribling, H.L. \& Carroll, J.P. (2006b) Home range, movement, and site fidelity of translocated northern bobwhite (Colinus virginianus) in southwest Georgia, USA. European Journal of Wildlife Research, $52,119-124$.
Teixeira, C.P., de Azevedo, C.S., Mendl, M., Cipreste, C.F. \& YounG, R.J. (2007) Revisiting translocation and reintroduction programmes: the importance of considering stress. Animal Behaviour, 73, 1-13.

Thacker, E.T., Hamm, R.L., Hagen, J., Davis, C.A. \& Guthery, F. (2016) Evaluation of the Surrogator ${ }^{\circledR}$ system to increase pheasant and quail abundance. Wildlife Society Bulletin, 40, 310-315.

Troy, R.J., Coates, P.S., Connelly, J.W., Gillette, G. \& Delehanty, D.J. (2013) Survival of mountain quail translocated from two distinct source populations. The Journal of Wildlife Management, 77, 1031-1037.

Zanette, L.Y., White, A.F., Allen, M.C. \& Clinchy, M. (2011) Perceived predation risk reduces the number of offspring songbirds produce per year. Science, 334, 1398-1401.

\section{Biographical sketches}

DAVE KeIter's research interests include the population ecology of invasive species, including the development of improved methods to study them, and the study and improvement of translocation procedures. BECKY RUZICKA's research is focused on the ecology of gallinaceous birds and the use of translocation to augment populations in decline. 